\title{
The Effect of Oat Bran on the Dough Rheology and Quality of Chinese Steamed Bread
}

\author{
LIU Wenjun, BRENNAN Margaret ${ }^{*}$, SERVENTI Luca, BRENNAN Charles
}

Department of Wine, Food and Molecular Biosciences, Faculty of Agriculture and Life Sciences, Lincoln University, Christchurch 7647, New Zealand

\begin{abstract}
The present study investigates the effects of incorporating oat bran (OB) into Chinese steamed bread (CSB). Different levels $(5 \%, 10 \%$ and $15 \%)$ of $\mathrm{OB}$ were used to replace wheat flour in the manufacture of CSB. The rheological properties of the dough were measured (water absorption (WA), development time, mixing tolerance, extensibility and stickiness). The addition of OB significantly increased WA, development time and stickiness, whereas decreased extensibility of dough. The physical properties of CSB were determined using specific volume, loaf height, moisture, and texture analysis. The nutritional quality of the bread was also analysed using an in vitro digestion method mimicking intestinal digestion. The results illustrated that the incorporation of OB into wheat flour decreases specific volume and softness of CSB. The addition of OB decreased the glycaemic response of steamed bread. This study illustrates the potential addition of OB to improve the nutritional quality of CSB.
\end{abstract}

Keywords: Oat bran; Dough rheology; Glycaemic response

\section{Introduction}

Oat bran $(\mathrm{OB})$ is a low-cost by-product produced during oat milling, and is a good source of dietary fibre $(\mathrm{DF})^{[1]}$. The main $\mathrm{DF}$ component of $\mathrm{OB}$ is $\beta$-glucan, which is a natural polymer composed of glucose molecules joined by $\beta-(1-3)$ and $\beta-(1-4)$ glycoside bonds ${ }^{[2-3]}$. $\beta$-glucan can easily form the viscous solutions and has been shown to slow the intestinal transit rate, delay gastric emptying and slow glucose and sterol absorption in the intestine ${ }^{[4]}$. Previous studies have illustrated that $\mathrm{OB}$ $\beta$-glucan has other beneficial effects, such as attenuation of postprandial blood glucose, reduction in insulin responses and a decrease in serum LDL cholesterol levels ${ }^{[5-6]}$. Additionally, $\mathrm{OB}$ has a potential role for disease prevention and control such as coronary heart disease, diabetes and obesity ${ }^{[7-8]}$.

Currently, consumers have a growing awareness of the link between diet and nutrition, thus there has been an increased demand for healthier products with a consequent rise in interest in functional and nutritional items by the food industry ${ }^{[9-12]}$. As a functional ingredient, DF has been proven to have many health beneficial effects and a potential role for disease prevention ${ }^{[13-16]}$ Therefore, at present the major goal of scientists is to incorporate the cereal brans into cereal-based and other food products in order to increase the intake of DF. OB is an important source of DF and common ingredient added to food products, especially bread. Most of studies in this area focus on Western bread, due to the addition of bran is detrimental to the baking performance ${ }^{[17]}$. Previous researches reported that the addition of OB led to higher water absorption (WA), sticker dough and lower loaf volume ${ }^{[17-18]}$. However, there is a paucity of information regarding the effect of

Received: 25 April 2018 /Accepted: 2 September 2018.

*Corresponding author. E-mail: margaret.brennan@lincoln.ac.nz CHenan University of Technology 2018

LIU W J, BRENNAN M, SERVENTI L, et al. The Effect of Oat Bran on the Dough Rheology and Quality of Chinese Steamed Bread[J]. Grain \& Oil Science and Technology, 2018, 1(3): 126-130.
OB on the quality of Chinese steamed bread (CSB).

CSB, also known as mantou, is a traditional fermented food and widely consumed as a staple food in China. Currently, steamed bread has widely spread to other Asian countries, North America and some European countries, and is estimated to account for around $15 \%$ of the wheat consumption in these regions ${ }^{[19]}$. Due to the differences in processing, the properties of CSB and Western style baked bread are significantly different. For instance, the flavours of CSB are formed during the fermentation, while the flavours of western style breads are derived during baking by Maillard reaction ${ }^{[20]}$. In addition, the lower processing temperature $\left(100^{\circ} \mathrm{C}\right)$ may result in the greater retention of nutrients in $\mathrm{CSB}^{[21]}$.

Hence, the present study investigated the effects of incorporating OB into CSB. Different levels (0, 5\%, $10 \%$ and $15 \%$ ) of OB were added into wheat flour. The quality of CSB was analysed from two perspectives: physical properties and nutritional quality. For physical properties, specific volume, loaf height, moisture, and texture were measured by AACC methods. The nutritional quality of the bread was analysed using the glycaemic response determined by an in vitro digestion method. The research aimed to determine whether the use of OB in CSB could provide CSB with similar physical properties to a control CSB, and also if the addition of OB could reduce the glycaemic response of the CSB hence improving its nutritional quality in terms of postprandial glycaemia.

\section{Materials and Methods}

\subsection{Materials and Reagents}

Wheat flour (Champion Flour Milling Ltd., Christchurch, New Zealand), Oat bran (Sun Valley Foods Ltd., Auckland, New Zealand), yeast powder and salt were purchased at the local supermarket (Table 1). Megazyme analysis kit (Megazyme International Ireland Ltd., Wicklow, Ireland) were used to determine starch content of the breads. 
Table 1 Nutrition information

\begin{tabular}{ccc}
\hline Per $100 \mathrm{~g}$ & Wheat flour $(\mathrm{g})$ & Oat bran $(\mathrm{g})$ \\
\hline Protein & 11.0 & 10.5 \\
Fat, total & 1.4 & 9.9 \\
- saturated & $<1$ & 2.0 \\
Carbohydrate & 77.3 & 44.3 \\
- sugars & $<1$ & 2.9 \\
Dietary fibre & 3.1 & 10.0 \\
Sodium & 0.005 & 0.003 \\
\hline
\end{tabular}

Note: Supplied by Sun Valley Foods Ltd. and Champion Flour Milling Ltd.

\subsection{Dough Rheological Analysis}

The dough rheological properties were measured using a Dough LAB (Perten Instruments Australia, Macquarie Park, Australia) following AACC standard method. A $300 \mathrm{~g}$ mixing bowl was used for all measurements and tests were performed at $(30 \pm 1)^{\circ} \mathrm{C}$. The weight of the dough ingredients was adjusted according to the moisture content of the samples to obtain consistency in moisture contents and WA (as is) was corrected to $500 \mathrm{FU}$. Dough development time, stability, softening, mixing tolerance index (MTI), and departure time were all measured using Dough LAB software (ver. 1.3.0.185). Analysis was performed three times.

\subsection{Preparation of CSB with OB}

CSB loaves were produced using the formulation of Lin et al. ${ }^{[20]}$ with some modifications. The recipe consisted of wheat flour $(200 \mathrm{~g})$, yeast powder $(4 \mathrm{~g})$, salt $(1 \mathrm{~g})$, and water (to give a maximum consistency of $500 \mathrm{FU}$ ). The dough and steamed bread were prepared by replacing wheat flour with different levels of OB $(5,10$ and $15 \mathrm{~g} / 100 \mathrm{~g} \mathrm{~W} / \mathrm{W}$ based on wheat flour dry weight). The dough was formed by using stand mixer (BBEK1092, Briscoes New Zealand Ltd.) for $5 \mathrm{~min}$ and kneading by hand for $5 \mathrm{~min}$, then it was rested at $28^{\circ} \mathrm{C}$ for $5 \mathrm{~min}$. After that, the dough pieces were divided into two portions, one was used for analysis of dough extension and stickiness, the other was kneaded for a further $8 \mathrm{~min}$ before fermentation in an incubator at $30{ }^{\circ} \mathrm{C}$ for $30 \mathrm{~min}$. After fermentation, the dough was rolled out, and allowed to rise at $30^{\circ} \mathrm{C}$ for $25 \mathrm{~min}$. Finally, the dough pieces were placed in a Convotherm mini easy Touch oven (CONVOTHERM Elektrogeräte GmbH, Germany) and steamed for $20 \mathrm{~min}$. Steamed bread loaves were cooled to room temperature and then analysed.

\subsection{Moisture Content Analysis}

Moisture content of the dough and bread was determined by an oven drying method $\left((105 \pm 2){ }^{\circ} \mathrm{C}\right.$ overnight $)$ described by AACC International Approved Method 44-16.01. The analysis was performed in triplicate and the results were expressed as $g$ water/100 g sample.

\subsection{Physical Properties of CSB Incorporated with OB}

Volume of steamed bread loaves were measured using the rapeseed displacement method, following the AACC International Approved Method 10-05.01. The measurements were carried out in triplicate.

The specific volume of steamed bread was calculated by dividing loaf volume by loaf weight, according to the AACCI Approved Method 10-05.01. The measurements were performed in triplicate.
The texture properties of steamed bread were determined using TA-XT2 Texture Analyser (Stable Micro Systems, Surrey, England) equipped with a $25 \mathrm{~mm}$ diameter cylinder probe.

\subsection{Total Starch Analysis}

The total starch determination of the steamed bread was carried out with the Megazyme Total Starch analysis kit (Megazyme International Ireland Ltd., Wicklow, Ireland) following AACCI Approved Method 76-13.01 as described by Brennan et al. ${ }^{[22]}$.

\subsection{Glycaemic Response Analysis}

In vitro Method Analysis: An in vitro glycaemic measurement as described by Brennan et al. ${ }^{[23]}$. Milled samples of bread were treated to in vitro using $10 \%$ pepsin dissolved in $0.05 \mathrm{~mol} / \mathrm{L} \mathrm{HCl}$ for $30 \mathrm{~min}$ at $37{ }^{\circ} \mathrm{C}$ under constant stirring to accomplish gastric digestion. Starch digestion was continued using $0.1 \mathrm{~mL}$ amyloglucosidase and $5 \mathrm{~mL}$ of $2.5 \%$ pancreatin in $0.1 \mathrm{~mol} / \mathrm{L} \mathrm{Na}$ maleate buffer $\mathrm{pH} 6$ at $37{ }^{\circ} \mathrm{C}$ for $120 \mathrm{~min}$ with constant mixing. Triplicate $1 \mathrm{~mL}$ aliquots were placed in $4 \mathrm{~mL}$ ethanol at 20,60 and $120 \mathrm{~min}$ and reducing sugar values were measured by the DNS method, using glucose references ${ }^{[24]}$. Each sample was measured in triplicate.

\subsection{Statistical Analysis}

All data were treated using analysis of variance (ANOVA) by using Minitab 17 statistical software, version 17.2.1 (Minitab Pty Ltd., Sydney) at Tukey's significant differences level $P<0.05^{[25]}$.

\section{Results and Discussion}

\subsection{Rheological Properties of Dough Incorporated with OB}

The effects of OB on the rheological properties of CSB dough are presented in Table 2. In terms of WA, there was a significant $(P<0.05)$ increase from $63.67 \%$ to $67.77 \%$ as the addition of OB levels increased from 0 to $15 \%$. Similar results were observed by Rieder et al. ${ }^{[26]}$ who observed that the substitution of wheat flour with OB significantly increased the WA due to the high fibre content. Dhinda et al. ${ }^{[27]}$ illustrated the addition of OB significantly increased the WA of wheat flour dough because of the high hydration property of DF. These observations can be attributed to the large number of hydroxyl groups in the structure of DF, which can interact with the hydrogen bonds of water ${ }^{[28-29]}$. The development time is the time taken for mixing the dough to reach the peak consistency ( $500 \mathrm{FU})$. The addition of $\mathrm{OB}$ increased the development time from 2.73 to $9.5 \mathrm{~min}$, whereas there was no significant difference between $10 \%$ and $15 \% \mathrm{OB}$. This observation is consistent with Rieder et al. ${ }^{[26]}$, who pointed out the inclusion of $\mathrm{OB}$ led to an increase in development time due to high water binding capacity of DF and disturbance of gluten network of DF. Krishnan et al. ${ }^{[18]}$ have illustrated that the addition of $10 \%$ and $15 \%$ OB to wheat flour can increase the dough development time. With regards to MTI and departure time, dough incorporated with OB has highervalues than wheat flour dough. This effect could be related to the high content of soluble fibre in OB. Similar effects on MTI 
and departure time were observed by Sudha et al. ${ }^{[30]}$ who reported that the addition of $\mathrm{OB}$ significantly increased the MTI. The dough stability results are presented in Table 2 . The highest stability value $(14.7 \mathrm{~min})$ was observed with the substitution level of 5\% OB. However, there was a significant decrease in the dough stability after the addition of $5 \% \mathrm{OB}$. This observation is consistent with the research of Liu et al. ${ }^{[31]}$ where the stability increased as the addition levels of bran increased from 0 to $5 \%$, and stability values decreased with levels of inclusion higher than $10 \%$.

\subsection{Extensiblity and Stickiness of Dough}

The effect of OB on the dough extensibility and stickiness are presented in Table 3 . The extensibility decreased significantly $(P<0.05)$ from 37.06 to $11.27 \mathrm{~mm}$ when the substitution of $\mathrm{OB}$ increased from 0 to $15 \%$. This effect could be related to the disruption of the starch-gluten network by OB. Similar results were observed by Rieder et al. ${ }^{[26]}$ who illustrated the addition of OB significantly decreased the extensibility and resistance to extension due to dilution of wheat gluten. In addition, Liu et al. ${ }^{[31]}$ pointed out the addition of bran reduced the dough extensibility owing to the interactions between fibre and wheat gluten. For the extension, a decrease was observed as the substitution of $15 \%$ $\mathrm{OB}$, although there was no significant difference between $5 \%$ and $10 \%$. Sudha et al. ${ }^{[32]}$ and Skendi et al. ${ }^{[33]}$ both illustrated that the addition of bran negatively affects the gluten network due to the disruption of starch-gluten matrix by bran. The effect could also be related to the percentage of bran added, the bran source, and particle size ${ }^{[34-36]}$.

Dough stickiness increased significantly $(P<0.05)$ from 46.22 to $54.87 \mathrm{~g}$ when the $\mathrm{OB}$ substitution increased from 0 to $15 \%$. Campbell et al. ${ }^{[17]}$ reported that the addition of OB increased the dough stickiness due to the higher content of soluble fibre ( $\beta$-glucan). This effect could be attributed to the unbound water in $\beta$-glucan and starch-gluten system. The excess water in the $\beta$-glucan and wheat gluten dough that is not bound by proteins and this seems to be responsible for the increased stickiness ${ }^{[37]}$.

\subsection{The Physical and Textural Properties of CSB}

Table 4 shows that the addition of OB to CSB influenced the physical properties of CSB from the specific volume, loaf height and moisture. In terms of specific volume and loaf height, a significant $(P<0.05)$ decrease was observed as the substitution of OB increased from 0 to $15 \%$. These observations are consistent with Rieder et al. ${ }^{[26]}$ who reported that the addition of wheat and OB led to a significant decrease in bread volume compared to bread made with wheat flour. Additionally, Liu et al. ${ }^{[31]}$ illustrated that the addition of wheat bran resulted in poor quality of CSB, such as a reduction of specific volume and loaf height. These observations can be attributed to the dilution of gluten in wheat flour-based dough and disrupting the hydration of gluten ${ }^{[20,27,31]}$. The moisture of CSB significantly increased when the substitution of OB increased due to the water holding capacity of $\mathrm{DF}^{[38-39]}$.

The influence of OB on the textural properties of CSB from hardness, springiness, cohesiveness, gumminess, chewiness and resilience are presented in Table 5. There was a significant $(P<0.05)$ increase in hardness, gumminess and chewiness as the substitution of $\mathrm{OB}$ increased from 0 to $15 \%$. Compared to control CSB, a slight increase was observed among 5\%, 10\% and $15 \%$, whereas there was no significant difference. In terms of cohesiveness and resilience, only CSB incorporated with $15 \%$ OB had lower values than control CSB, while no significant differences were observed among $0,5 \%$ and $10 \%$. Similar trend was observed by Liu et al. ${ }^{[31]}$, who illustrated that the addition of bran increased the hardness, gumminess and chewiness of CSB, whereas reduced the springiness and cohesiveness. In addition, Rieder et al. ${ }^{[26]}$ reported that bread incorporated with $\mathrm{OB}$ had a higher crumb firmness than wheat bread owing to the $\beta$-glucan content and molecular weight. Previous research has illustrated that OB has a higher molecular weight of $\beta$-glucan than oat four, this $\beta$-glucan may disrupt the reaction between starch and protein in wheat flour, resulting in the CSB being hard and less springy ${ }^{[20,31,40-42]}$.

Table 2 The rheology of dough incorporated with OB

\begin{tabular}{ccccccc}
\hline Sample & WA (\%) & Stability (min) & Development time (min) & Softening (FU) & Departure time (min) & MTI (FU) \\
\hline Wheat flour & $63.67 \pm 0.11^{\mathrm{D}}$ & $11.17 \pm 0.47^{\mathrm{C}}$ & $2.73 \pm 0.06^{\mathrm{C}}$ & $41.46 \pm 4.11^{\mathrm{A}}$ & $12.72 \pm 0.85^{\mathrm{B}}$ & $10.51 \pm 1.10^{\mathrm{B}}$ \\
Wheat flour + 5\% OB & $64.73 \pm 0.11^{\mathrm{C}}$ & $14.70 \pm 0.60^{\mathrm{A}}$ & $7.73 \pm 0.21^{\mathrm{B}}$ & $37.83 \pm 1.34^{\mathrm{A}}$ & $16.60 \pm 0.53^{\mathrm{A}}$ & $21.83 \pm 1.27^{\mathrm{A}}$ \\
Wheat flour + 10\% OB & $66.30 \pm 0.17^{\mathrm{B}}$ & $12.73 \pm 0.11^{\mathrm{B}}$ & $9.26 \pm 0.31^{\mathrm{A}}$ & $37.90 \pm 1.04^{\mathrm{A}}$ & $16.93 \pm 0.11^{\mathrm{A}}$ & $20.06 \pm 0.25^{\mathrm{A}}$ \\
Wheat flour + 15\% OB & $67.77 \pm 0.45^{\mathrm{A}}$ & $10.50 \pm 0.36^{\mathrm{C}}$ & $9.50 \pm 0.20^{\mathrm{A}}$ & $38.63 \pm 0.38^{\mathrm{A}}$ & $16.13 \pm 0.06^{\mathrm{A}}$ & $22.20 \pm 0.91^{\mathrm{A}}$ \\
\hline
\end{tabular}

Note: Values are means \pm standard deviations $(n=3)$. Values in the same column with different letters differ significantly $(P<0.05)$. WA: water absorption,

MTI: mixing tolerance index, OB: oat bran.

Table 3 Extensibility and stickiness of dough incorporated with OB

\begin{tabular}{|c|c|c|c|c|}
\hline Dough samples & Stickiness (g) & Cohesiveness (mm) & Extension(g) & Extensibility (mm) \\
\hline Control & $46.22 \pm 1.94^{\mathrm{C}}$ & $4.46 \pm 0.72^{\mathrm{A}}$ & $38.99 \pm 4.78^{\mathrm{A}}$ & $37.06 \pm 0.51^{\mathrm{A}}$ \\
\hline Dough $+5 \%$ OB & $48.63 \pm 0.78^{\mathrm{BC}}$ & $2.73 \pm 0.14^{\mathrm{B}}$ & $37.80 \pm 0.28^{\mathrm{A}}$ & $17.35 \pm 0.28^{\mathrm{B}}$ \\
\hline Dough $+10 \%$ OB & $51.26 \pm 0.31^{\mathrm{B}}$ & $2.63 \pm 0.03^{\mathrm{B}}$ & $37.51 \pm 1.17^{\mathrm{A}}$ & $14.36 \pm 0.23^{\mathrm{C}}$ \\
\hline Dough $+15 \%$ OB & $54.87 \pm 0.53^{\mathrm{A}}$ & $3.12 \pm 0.21^{\mathrm{B}}$ & $21.55 \pm 0.24^{\mathrm{B}}$ & $11.27 \pm 0.16^{\mathrm{D}}$ \\
\hline
\end{tabular}

Note: Values are means \pm standard deviations $(n=3)$. Values in the same column with different letters differ significantly $(P<0.05)$. OB: oat bran.

Table 4 The physical properties of CSB incorporated with OB

\begin{tabular}{|c|c|c|c|}
\hline CSB samples & Loaf height $(\mathrm{mm})$ & Specific volume $(\mathrm{mL} / \mathrm{g})$ & Moisture (g water/100 g sample) \\
\hline Control & $62.14 \pm 0.38^{\mathrm{A}}$ & $2.47 \pm 0.03^{\mathrm{A}}$ & $40.10 \pm 0.01^{\mathrm{D}}$ \\
\hline $\mathrm{CSB}+5 \% \mathrm{OB}$ & $54.03 \pm 0.52^{\mathrm{B}}$ & $2.17 \pm 0.01^{\mathrm{B}}$ & $44.88 \pm 0.07^{\mathrm{C}}$ \\
\hline $\mathrm{CSB}+10 \% \mathrm{OB}$ & $50.29 \pm 0.16^{\mathrm{C}}$ & $2.05 \pm 0.01^{\mathrm{C}}$ & $45.14 \pm 0.09^{\mathrm{B}}$ \\
\hline $\mathrm{CSB}+15 \% \mathrm{OB}$ & $41.08 \pm 0.56^{\mathrm{D}}$ & $1.80 \pm 0.01^{\mathrm{D}}$ & $45.55 \pm 0.16^{\mathrm{A}}$ \\
\hline
\end{tabular}

Note: Values are means \pm standard deviations $(n=3)$. Values in the same column with different letters differ significantly $(P<0.05)$. OB: oat bran. 
Table 5 The textural properties of CSB with OB

\begin{tabular}{|c|c|c|c|c|c|c|}
\hline Samples & Hardness (g) & Springiness (ratio) & Cohesiveness (ratio) & Gumminess (g) & Chewiness (g) & Resilience (ratio) \\
\hline Control & $228.24 \pm 25.92^{\mathrm{D}}$ & $0.94 \pm 0.01^{\mathrm{B}}$ & $0.88 \pm 0.01^{\mathrm{A}}$ & $191.75 \pm 19.15^{\mathrm{D}}$ & $179.83 \pm 19.34^{\mathrm{D}}$ & $0.57 \pm 0.01^{\mathrm{A}}$ \\
\hline $\mathrm{CSB}+5 \% \mathrm{OB}$ & $326.19 \pm 6.26^{\mathrm{C}}$ & $0.98 \pm 0.01^{\mathrm{A}}$ & $0.88 \pm 0.01^{\mathrm{A}}$ & $288.15 \pm 2.22^{\mathrm{C}}$ & $279.91 \pm 8.98^{\mathrm{C}}$ & $0.59 \pm 0.01^{\mathrm{A}}$ \\
\hline $\mathrm{CSB}+10 \% \mathrm{OB}$ & $425.81 \pm 13.19^{\mathrm{B}}$ & $0.98 \pm 0.01^{\mathrm{A}}$ & $0.88 \pm 0.01^{\mathrm{A}}$ & $370.83 \pm 5.98^{\mathrm{B}}$ & $365.85 \pm 10.70^{\mathrm{B}}$ & $0.59 \pm 0.01^{\mathrm{A}}$ \\
\hline $\mathrm{CSB}+15 \% \mathrm{OB}$ & $521.12 \pm 10.79^{\mathrm{A}}$ & $0.98 \pm 0.01^{\mathrm{A}}$ & $0.85 \pm 0.01^{\mathrm{B}}$ & $469.59 \pm 15.80^{\mathrm{A}}$ & $446.98 \pm 19.76^{\mathrm{A}}$ & $0.56 \pm 0.01^{\mathrm{B}}$ \\
\hline
\end{tabular}

Note: Values are means \pm standard deviations $(n=3)$. Values in the same column with different letters differ significantly $(P<0.05)$; OB: oat bran.

\subsection{Predicted Glycemic Impact of CSB Incorporated with OB}

The total starch content of CSB with OB is presented in Table 6. There was a decrease in total starch content when the substitution of $\mathrm{OB}$ increased from 0 to $15 \%$. Compared to the control, CSB incorporated with $15 \%$ OB had a lower starch content $(37.52 \%)$. The values of reducing sugars released during the in vitro digestion of all CSB samples over $120 \mathrm{~min}$ is shown in Fig. 1. The results give a good indication of the rate of starch degradation and allow the calculation of a predictive glycaemic index of samples. From the results, there was a trend to reduce the starch degradation as the substitution level of OB increased. Similar results were observed by Foschia et al. ${ }^{[43]}$ and Lindström et al. ${ }^{[44]}$ who pointed out food products containing OB can reduce the postprandial blood glucose response. The area under the glucose release curve is a calculation of predicted glycaemic response for $2 \mathrm{~h}$ after food consumption [24, 45-46]. Table 6 shows that the addition of OB decreased the AUC values and CSB substituted with $15 \%$ OB had the lowest value (344.61). This effect can be related to $\beta$-glucan, as a water-soluble fibre, which can easily form the viscous solutions, thus slows the intestinal transit, delays gastric emptying and slows glucose and sterol absorption in the intestine $e^{[47-48]}$.

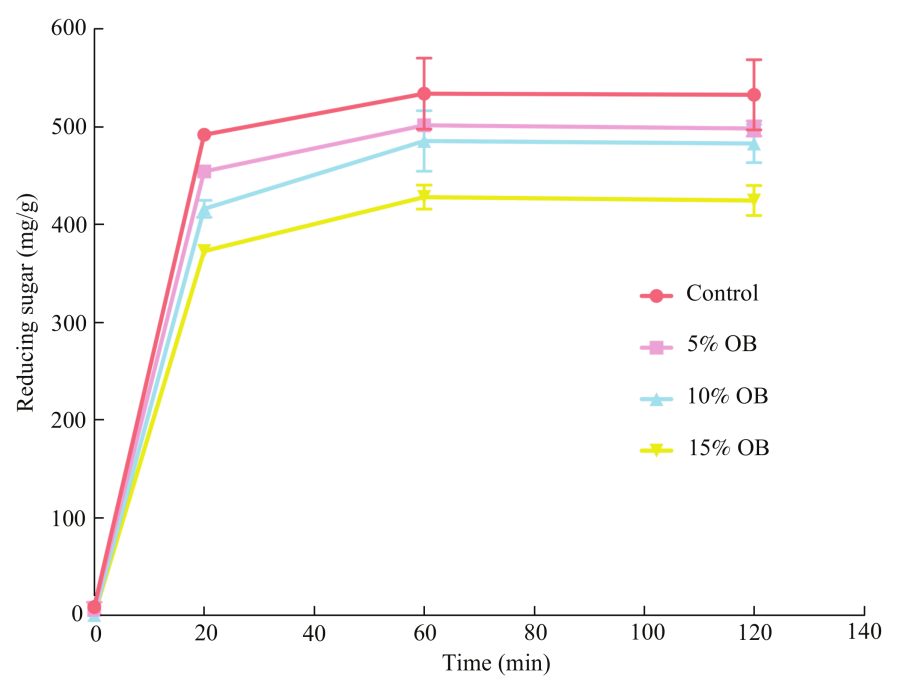

Fig. 1 Reducing sugar released during in vitro digestion of CSB OB: oat bran.

Table 6 Total starch and AUC value of CSB with OB

\begin{tabular}{ccc}
\hline Samples & Total starch $(\%)$ & \multicolumn{1}{c}{ AUC values } \\
\hline Control & $43.82 \pm 1.30^{\mathrm{A}}$ & $431.51 \pm 31.80^{\mathrm{A}}$ \\
CSB $+5 \%$ OB & $40.65 \pm 0.05^{\mathrm{B}}$ & $399.13 \pm 3.31^{\mathrm{AB}}$ \\
CSB $+10 \%$ OB & $39.06 \pm 0.38^{\mathrm{BC}}$ & $383.29 \pm 17.40^{\mathrm{BC}}$ \\
CSB $+15 \%$ OB & $37.52 \pm 0.26^{\mathrm{C}}$ & $344.61 \pm 2.81^{\mathrm{C}}$
\end{tabular}

Note: Values are means \pm standard deviations $(n=3)$. Values in the same column with different letters differ significantly $(P<0.05)$. AUC-predicted glycaemic response; OB: oat bran.
In addition, Foschia et al. ${ }^{[43]}$ has found that DF can combine with proteins and form a matrix barrier surrounding the starch granules to reduce the enzymes activity.

\section{Conclusions}

This study illustrates that addition of OB into wheat flour can influence the dough rheology and final quality of CSB due to the high hydration properties of DF and the disruption of the starch-gluten network by DF. This then affects the quality of CSB such as density, volume and texture. Additionally, the results also show that addition of $\mathrm{OB}$ led to a reduction of predicted glycaemic response. As such, findings of the present research are of great importance to the food industry as it is possible to use $\mathrm{OB}$ as a functional ingredient in food industry with many health benefits for consumer.

\section{Conflict of Interest}

The authors declare that there is no conflict of interest.

\section{References}

[1] ZHANG M, BAI X, ZHANG Z. Extrusion process improves the functionality of soluble dietary fiber in oat bran[J]. Journal of Cereal Science, 2011, 54(1): 98-103.

[2] SADIQ BUTT M, TAHIR-NADEEM M, KHAN M K, et al. Oat: unique among the cereals[J]. European Journal of Nutrition, 2008, 47(2): 68-79.

[3] CHATUEVEDI N, YADAV S, SHUKLA K. Diversified therapeutic potential of Avena sativa: An exhaustive review[J]. Asian Journal of Plant Science and Research, 2011, 1(3): 103-114.

[4] KATONGOLE J. Aqueous protein based extraction of oat beta glucan and its physiological effects on satiety and glycaemic responses in healthy adults[D]. Guelph: University of Guelph, 2012.

[5] WOOD P. J. Oat and rye $\beta$-glucan: Properties and function[J]. Cereal Chemistry, 2010, 87(4): 315-330.

[6] EL KHOURY D, CUDA C, LUHOVYY B L, et al. Beta glucan: health benefits in obesity and metabolic syndrome[J]. Journal of Nutrition and Metabolism, 2011, 2012: 851362.

[7] CAVAZOS A, GONZALEZ DE MEJIA E. Identification of bioactive peptides from cereal storage proteins and their potential role in prevention of chronic diseases[J]. Comprehensive Reviews in Food Science and Food Safety, 2013, 12(4): 364-380.

[8] HASLER C M. Functional foods: their role in disease prevention and health promotion[J]. Food Technology, 1998, 52: 63-147.

[9] BRENNAN M, MERTS I, MONRO J, et al. Impact of guar and wheat bran on the physical and nutritional quality of extruded breakfast cereals[J]. Starch - Stärke, 2008, 60(5): 248-256.

[10] MCGILL C R, DEVAREDDY L. Ten-year trends in fiber and whole grain intakes and food sources for the United States population: National Health and Nutrition Examination Survey 2001-2010[J]. Nutrients, 2015, 7(2): 1119-1130.

[11] CHAREONTHAIKIJ P, UAN-ON T, PRINYAWIWATKUL W. Effects of pineapple pomace fibre on physicochemical properties of composite flour and dough, and consumer acceptance of fibre-enriched wheat bread[J]. International Journal of Food Science \& Technology, 2016, 51(5): 1120-1129.

[12] GRIGOR J M, BRENNAN C S, HUTCHINGS S C, et al. The sensory acceptance of fibre-enriched cereal foods: a meta-analysis[J]. 
International Journal of Food Science \& Technology, 2016, 51(1): 3-13.

[13] THREAPLETON D E, GREENWOOD D C, EVANS C E L, et al. Dietary fibre intake and risk of cardiovascular disease: systematic review and meta-analysis[J]. British Medical Journal, 2013, 347: f6879.

[14] DHINGRA D, MICHAEL M, RAJPUT H, et al. Dietary fibre in foods: A review[J]. Journal of Food Science and Technology, 2012, 49(3): 255-266.

[15] AUNE D, CHAN D S M, LAU R, et al. Dietary fibre, whole grains, and risk of colorectal cancer: systematic review and dose-response meta-analysis of prospective studies[J]. British Medical Journal, 2011, 343: d6617.

[16] ELLEUCH M, BEDIGIAN D, ROISEUX O, et al. Dietary fibre and fibre-rich by-products of food processing: characterisation, technological functionality and commercial applications: a review[J]. Food Chemistry, 2011, 124(2): 411-421.

[17] CAMPBELL G M, ROSS M, MOTOI L. Bran in bread: effects of particle size and level of wheat and oat bran on mixing, proving and baking[M]// Bubbles in Food 2. Elsevier Inc., 2008: 337-354.

[18] KRISHNAN P G, CHANG K C, BROWN G. Effect of commercial oat bran on the characteristics and composition of bread[J]. Cereal Chemistry, 1987, 64(1): 55-58.

[19] WU C, LIU R, HUANG W, et al. Effect of sourdough fermentation on the quality of Chinese Northern-style steamed breads[J] Journal of Cereal Science, 2012, 56(2): 127-133.

[20] LIN S Y, CHEN H H, LU S, et al. Effects of blending of wheat flour with barley flour on dough and steamed bread properties[J]. Journal of Texture Studies, 2012, 43(6): 438-444.

[21] ZHU F, SAKULNAK R, WANG S. Effect of black tea on antioxidant, textural, and sensory properties of Chinese steamed bread[J]. Food chemistry, 2016, 194: 1217-1223.

[22] BRENNAN M A, MONRO J A, BRENNAN C S. Effect of inclusion of soluble and insoluble fibres into extruded breakfast cereal products made with reverse screw configuration[J]. International Journal of Food Science \& Technology, 2008, 43(12): 2278-2288.

[23] BRENNAN M A, DERBYSHIRE E, TIWARI B K, et al. Ready-to-eat snack products: the role of extrusion technology in developing consumer acceptable and nutritious snacks[J]. International Journal of Food Science \& Technology, 2013, 48(5): 893-902.

[24] MONRO J A, MISHRA S, VENN B. Baselines representing blood glucose clearance improve in vitro prediction of the glycaemic impact of customarily consumed food quantities[J]. British Journal of Nutrition, 2010, 103(2): 295-305.

[25] JENSEN W A. Response surface methodology: process and product optimization using designed experiments[J]. Journal of Quality Technology, 2017, 49(2): 186.

[26] RIEDER A, HOLTEKJØLEN A K, SAHLSTRØM S, et al. Effect of barley and oat flour types and sourdoughs on dough rheology and bread quality of composite wheat bread[J]. Journal of Cereal Science, 2012, 55(1): 44-52.

[27] DHINDA F, A. J L, PRAKASH J. Effect of ingredients on rheological, nutritional and quality characteristics of high protein, high fibre and low carbohydrate bread[J]. Food and Bioprocess Technology, 2012, 5(8): 2998-3006.

[28] ROBERTSON J A, DE MONREDON F D, DYSSELER P, et al. Hydration properties of dietary fibre and resistant starch: a European collaborative study[J]. LWT-Food Science and Technology, 2000, 33(2): 72-79.

[29] ROSELL C M, SANTOS E, COLLAR C. Mixing properties of fibre-enriched wheat bread doughs: A response surface methodology study[J]. European Food Research and Technology, 2006, 223(3): 333-340.

[30] SUDHA M L, VETRIMANI R, LEELAVATHI K. Influence of fibre from different cereals on the rheological characteristics of wheat flour dough and on biscuit quality[J]. Food Chemistry,
2007, 100(4): 1365-1370.

[31] LIU W, BRENNAN M, SERVENTI L, et al. Effect of wheat bran on dough rheology and final quality of Chinese steamed bread[J]. Cereal Chemistry, 2017, 94(3): 581-587.

[32] SUDHA M L, RAJESWARI G, VENKATESWARA RAO G. Effect of wheat and oat brans on the dough rheological and quality characteristics of instant vermicelli[J]. Journal of Texture Studies, 2012, 43(3): 195-202.

[33] SKENDI A, BILIADERIS C G, PAPAGEORGIOU $\mathrm{M}$, et al. Effects of two barley $\beta$-glucan isolates on wheat flour dough and bread properties[J]. Food Chemistry, 2010, 119(3): 1159-1167.

[34] KIEFFER R, LOOKHART G, NG P. Modification of gluten by emulsifiers and effects on dough stabilization, September 14-16, 2006[C]. San Fransisco: American Association of Cereal Chemists, Inc (AACC), 2007.

[35] LE BLEIS F, CHAUNIER L, CHIRON H, et al. Rheological properties of wheat flour dough and French bread enriched with wheat bran[J]. Journal of Cereal Science, 2015, 65: 167-174.

[36] JACOBS P J, HEMDANE S, DORNEZ E, et al. Study of hydration properties of wheat bran as a function of particle size[J]. Food Chemistry, 2015, 179: 296-304.

[37] AHMED J, THOMAS L. Effect of $\beta$-glucan concentrate on the water uptake, rheological and textural properties of wheat flour dough[J]. International Journal of Food Properties, 2015, 18(8): 1801-1816.

[38] GÜLER-AKIN M B, FERLIARSLAN I, AKIN M S. Apricot probiotic drinking yoghurt supplied with inulin and oat fiber[J]. Advances in Microbiology, 2016, 6(14): 999.

[39] SETTE P, CALVACHE J E N, SORIA M, et al. Impact of different factors on the yield and properties of fractions enriched in dietary fiber isolated from peach (Prunus persica $L$.) residues[J]. Open Agriculture, 2016, 1(1): 45-54.

[40] ÅMAN P, RIMSTEN L, ANDERSSON R. Molecular weight distribution of $\beta$-glucan in oat-based foods[J]. Cereal Chemistry, 2004, 81(3): 356-360.

[41] KERCKHOFFS D A J M, HORNSTRA G, MENSINK R P. Cholesterol-lowering effect of $\beta$-glucan from oat bran in mildly hypercholesterolemic subjects may decrease when $\beta$-glucan is incorporated into bread and cookies[J]. The American Journal of Clinical Nutrition, 2003, 78(2): 221-227.

[42] LIU W, BRENNAN M, SERVENTI L, et al. Buckwheat flour inclusion in Chinese steamed bread: potential reduction in glycemic response and effects on dough quality[J]. European Food Research and Technology, 2017, 243(5): 727-734.

[43] FOSCHIA M, PERESSINI D, SENSIDONI A, et al. Synergistic effect of different dietary fibres in pasta on in vitro starch digestion?[J]. Food Chemistry, 2015, 172: 245-250.

[44] LINDSTRÖM C, VOINOT A, FORSLUND A, et al. An oat bran-based beverage reduce postprandial glycaemia equivalent to yoghurt in healthy overweight subjects[J]. International Journal of Food Sciences and Nutrition, 2015, 66(6): 700-705.

[45] MONRO J A, SHAW M. Glycemic impact, glycemic glucose equivalents, glycemic index, and glycemic load: definitions, distinctions, and implications[J]. The American journal of clinical nutrition, 2008, 87(1): 237S-243S.

[46] MONRO J A. Glycaemic glucose equivalent: combining carbohydrate content, quantity and glycaemic index of foods for precision in glycaemia management [J]. Asia Pacific Journal of Clinical Nutrition, 2002, 11(3): 217-225.

[47] ABUMWEIS S, THANDAPILLY S J, STORSLEY J, et al. Effect of barley $\beta$-glucan on postprandial glycaemic response in the healthy human population: a meta-analysis of randomized controlled trials $[\mathrm{J}]$. Journal of Functional Foods, 2016, 27: 329-342.

[48] PÉREZ-QUIRCE S, LAZARIDOU A, BILIADERIS C G, et al. Effect of $\beta$-glucan molecular weight on rice flour dough rheology, quality parameters of breads and in vitro starch digestibility[J]. LWT-Food Science and Technology, 2017, 82: 446-453. 